\title{
DIREITO GREGO? POSITIVIDADE, PROBLEMATICIDADE E DECISÃO NA EXPERIÊNCIA JURÍDICA GREGA ANTIGA
}

\author{
Nuno M. M. S. \\ Coelho ${ }^{1}$ \\ Sebastião Trogo ${ }^{2}$
}

\begin{abstract}
Resumo
A partir da concepção de direito de Niklas Luhmann e Tercio Sampaio Ferraz Jr. - que assinalam o caráter dogmático do pensamento jurídico, comprometido com a decidibilidade e marcado pela problematização de fatos e normas - este artigo investiga aspectos do pensamento político grego antigo, tentando compreender em que medida se encontram, na cultura ateniense dos séculos V que IV a. C., traços especificadores do pensamento jurídico.

Palavras-chave: Grécia Antiga. Direito. Pensamento jurídico. Cultura filosófica.
\end{abstract}

\section{INTRODUÇÃO: DIREITO COMO PENSAMENTO PROBLEMATIZADOR: CARACTERÍSTICAS FUNDAMENTAIS}

Com Niklas Luhmann (1972) e Tercio Sampaio Ferraz Jr. (1988), admitamos que o pensamento dos juristas é um saber do tipo dogmático. O jurista lida com pontos de partida que não podem ser questionados: são dogmas. Os critérios a partir dos quais o jurista pensa, e decide, são dados. Mas para fazer com que estes pontos de partida ofereçam resposta a conflitos sempre mais numerosos e complexos, o jurista os submete a uma reconstrução lógica, hermenêutica e retórica muito sofisticada. Esta apropriação e reconstrução feita pelo jurista, a esclarecer nos próximos parágrafos, é de tal monta que o leigo (que não pensa como o jurista) muitas vezes não é capaz de compreender como o jurista pôde chegar à conclusão a que chegou, a partir daqueles pontos de partida.

\section{Pensamento jurídico como mediação entre leis, fatos e decisão judicial}

\footnotetext{
${ }^{1}$ Professor de Graduação e Pós Graduação da FDRP-USP. Doutor em Direito pela Universidade Federal de Minas Gerais, e Livre-Docência em Direito pela Universidade de São Paulo na área de Teoria e Filosofia do Direito, com Estágios Doutorais junto à Faculdade de Direito de Coimbra e junto à Faculdade de Letras/Centro de Filosofia da Universidade de Lisboa. E-mail: nunocoelho@usp.br

${ }^{2}$ Doutor em Filosofia das Relações Intersubjetivas pela Universite Catholique de Louvain (1979). Professor títular da Faculdade de Estudos Administrativos de Minas Gerais e diretor geral da Faculdade de Direito Conselheiro Lafaiete. E-mail: trogo@gmail.com
} 
O pensamento do jurista prepara, a partir do caso, as condições para a emissão de uma decisão. Graças a ele, surge um mundo de distinções, condições, mitigações e agravantes, que transformam o sentido da lei e dos fatos debatidos. O pensamento do jurista se interpõe entre caso e decisão, e também entre lei e decisão, e faz toda diferença: a decisão deixa de ser considerada como simples repetição da lei, e tampouco é mais reconhecida como confirmação de uma lógica presente nos fatos em causa.

Reconstruindo a reflexão luhmanniana sobre o surgimento do pensamento jurídico na Antiguidade, Ferraz Jr. esclarece o conceito central do pensamento jurídico: a decidibilidade.

A decidibilidade expressa um diferente estágio no modo como as sociedades humanas concebem a relação do ser humano com a ordem normativa. Abre-se espaço para a discussão do significado jurídico das condutas, o qual passa a ser concebido como problema. Como esclarece Ferraz Jr. (1998, p. 31):

Graças a ela, as pretensões normativas que, em sociedades primitivas, têm uma imediatidade expressiva (isto é, ou estamos no Direito, ou estamos excluídos socialmente), perdem este caráter, relacionando-se claramente a regras e valores aceitos por todos, na expectativa de continuidade da vida social. Com isto, são criadas possibilidades para que o chamado comportamento desviante também tenha seu lugar, permitindo-se ao delinquente uma argumentação com os mesmos valores e regras no intuito de neutralizar, simbolicamente, seu próprio comportamento.

Surge assim a nota característica do pensamento jurídico: a abertura argumentativa para a problematização dos fatos e dos critérios da convivência. Esta problematização permite colocar em questão, ou melhor, em confronto, diferentes perspectivas acerca do que ocorreu e/ou do que significa a lei. Desta situação de confronto e problematicidade surge a necessidade de uma decisão, que passa a ser o ponto de referência de todo pensamento jurídico. A técnica dos juristas se desenvolve com a consciência de que a discussão sobre as leis e os fatos em julgamento é constitutiva da decisão. Isto é, de que o julgamento não é imanente aos fatos e às leis, mas se constrói a partir da sua problematização.

Historicamente, o surgimento da dogmática jurídica relaciona-se com o incremento da complexidade da sociedade, desenvolvendo-se por instâncias linguísticas mais sofisticadas e especializadas.

A instituição de tribunais está associada a este processo, em que a discussão sobre normas e valores, a propósito das ações em julgamento, possibilita a discussão sobre a própria sociedade. Tal como escreve Ferraz Jr. (Cit., p. 31) acerca deste ponto entre os romanos, a 
sociedade "julga a si mesma através dos processos jurídicos":

Nestes processos, o juiz, que nem é um mágico, nem um guarda de rituais, torna-se alguém que decide e responde por sua decisão enquanto juiz. Para que isto fosse possível, por sua vez, o Direito teria de alcançar, como de fato pouco a pouco alcançou, um nível de abstração maior, tornando-se um regulativo abstrato capaz de acolher indagações a respeito de divergentes pretensões jurídicas. Ou seja: o direito assumiu a forma de um programa decisório no qual eram formuladas as condições para uma decisão correta. (FERRAZ Jr., 1998, p. 31).

Isto significa que as normas deixam de ser compreendidas como forças imanentes que regulam os comportamentos e as reações da sociedade à conduta desviante, para conceberemse como elementos do processo decisório - processo decisório do qual a sentença passa a depender essencialmente. Entre a conduta e o julgamento, deixa de haver uma relação de imediatidade e de aproblematicidade, ou de necessidade. Neste espaço, insere-se agora o exercício de um pensar que os liga, mas não sem instituir e remarcar a sua diferença.

Mais uma vez referindo-se aos romanos, Ferraz Jr. aponta "um distanciamento dos procedimentos decisórios concretos em relação à ordem normativa", inaugurando uma distinção fundamental do pensamento dos juristas, entre questão de fato e questão de direito. Isto "permite que não se veja o Direito como assentado concretamente nos próprios eventos, mas em normas tomadas como critério para posterior julgamento à vista dos fatos." (FERRAZ JR., 1998, p. 32):

Isto significa que a interpretação do Direito, alvo máximo da Dogmática em desenvolvimento, destaca-se do caso concreto, constituindo uma discussão por si com critérios próprios, abstratos se comparados à experiência das disputas do dia-a-dia. Em outras palavras, o estabelecimento de fatos relevantes para o Direito passa a ser uma questão jurídica e não um problema imanente aos fatos. (FERRAZ JR., 1998, p. 32).

O pensamento jurídico especifica-se enquanto exercício do logos que realiza esta mediação.

A racionalidade dos juristas desenvolve-se a partir das disputas e dos esforços por responder aos casos. Ao fazê-lo, os juristas se apropriam da lei, a que impõem seus esquemas interpretativos (construídos na história de casos passados) - da mesma forma como impõem aos fatos suas classificações, ficções, presunções etc. - reconstruindo-os de sorte a preparar as condições para a decisão.

$\mathrm{Na}$ descrição esquemática proposta por Ferraz Jr., o pensamento do jurista, ao apropriar-se de fatos e leis para preparar a decisão, compõe-se por três etapas: 1) uma Dogmática Analítica (em que o pensamento jurídico empenha-se em descobrir quais textos vol.09, n. 03, Rio de Janeiro, 2016. pp. 
podem amparar a decisão - nesta fase, o pensamento jurídico mobiliza seus critérios de solução de anomias, de antinomias, seus padrões hierárquicos e sistemáticos etc.); 2) uma Dogmática Hermenêutica (momento em que o pensamento jurídico, já de posse do texto a mobilizar para decidir, empenha-se em interpretá-lo - nesta fase, o pensamento jurídico mobiliza seus instrumentos hermenêuticos, como cânones e princípios de interpretação); 3) e uma Dogmática da Decisão (fase em que o jurista dá, ao material que levantou e interpretou nas fases anteriores, o tratamento retórico-argumentativo). ${ }^{3}$

O surgimento deste tipo de pensamento coincide (mas não se confunde) com o florescimento da Ciência do Direito ${ }^{4}$, mas a ela se liga essencialmente. A Ciência do Direito pode ser concebida como uma instância sistematizadora (e em permanente reconstrução) dos elementos construídos pelos juristas, no exercício concreto da Dogmática Jurídica como pensamento voltado para o decidir.

\section{A contribuição grega à invenção do pensamento jurídico}

A instituição do hiato entre as premissas legais e fáticas do caso e a decisão judicial

Acreditamos encontrar, na experiência da lei e do decidir na Polis dos séculos V e IV a.C., e tomando Atenas como cenário privilegiado, as condições de possibilidade deste tipo de pensamento, lançando as primeiras bases da história da Ciência do Direito - que depois encontraria, na experiência jurídica romana, enorme impulso. ${ }^{5}$

\footnotetext{
${ }^{3}$ É claro que a separação do pensamento jurídico em três fases distintas, tal como o faz Ferraz Jr., atende antes a critérios didáticos que científicos (anote-se que tal construção estrutura seu livro de Introdução ao Direito). Sabemos que se trata de processos sempre contemporâneos e interligados (descobrir que texto é útil para julgar, que integra a Dogmática Analítica, não se faz sem interpretá-lo, que integra a Dogmática Hermenêutica, por exemplo). Mas sua construção tem o mérito de mostrar que todo o arcabouço do saber que estrutura o pensamento do jurista está a serviço da construção da decisão, que se mantém como o telos de todo raciocínio jurídico.

${ }^{4} \mathrm{O}$ direito como racionalidade problematizadora de fatos e normas, preparadora da decisão, não se confunde com a ciência do direito, uma vez que esta é uma instância sistematizadora do que a prática jurídica produz em seu processo de autoconstrução e reprodução histórica. Deixamos de lado, neste momento, a discussão acerca do papel da ciência do direito em sua influência sobre a prática jurídica, que não deve ser todavia ignorada.

${ }^{5}$ Não se trata de um ponto de vista evolucionário para a compreensão da história. Acompanhamos Cohen em sua crítica às perspectivas historiográficas evolucionárias aplicadas à história do direito, que impõem modelos esquemáticos para a compreensão do processo de surgimento das ordens jurídicas e dos tribunais: "Evolutionary accounts offer historical explanations of how such equilibrium-maintaining instituions arise. They usually portray these institutions as representing particular 'stages' on the path from the presumed chaos of an acephalous society to the harmonious order of the fully developed rule of law as embodied in modern democratic states." (COHEN, 1997, p. 5-6). "The problem with evolutionary theories have to do with their teleological impetus, with their tendency to see developments as the product of an inevitable 'evolution' and hence not requiring particular 'stage' is seen as neatly 'replacing' another" (p. 14). As advertências de
} 
A presença de elementos constituintes da racionalidade jurídica, entre os gregos, explorada neste artigo, revela a sua gênese retórica, e assim o caráter incontornavelmente argumentativo deste saber/pensar que passaria a distinguir a comunidade dos juristas em seu compromisso com a decisão dos casos. À estrutura dialógica-argumentativa (contraditória) do pensamento jurídico liga-se o surgimento de muitos dos problemas, categorias, conceitos e classificações construídos pelos juristas para dar conta do desafio da decidibilidade, como veremos.

Textos do séc. V a.C. - da retórica política e forense, e da filosofia, em Atenas sinalizam que o pensamento jurídico torna-se consciente de si enquanto logos comprometido com a construção de uma decisão. A descoberta da finitude, da contraposição e da parcialidade do pensamento humano impõe um problema de todo novo à experiência do julgar e permite que o pensamento jurídico comece a formar-se na medida em que se apresenta como explícita problematização da lei e dos fatos em julgamento, como logos que conscientemente reconstrói fatos e normas. Esta reconstrução é imposta pelo caráter contraditório (antilógico, dissídico) da argumentação jurídica e é assumida como constitutiva da decisão.

A decisão jurídica passa, assim, a manter relação problemática com os pontos de partida da argumentação, que devem ser reapropriados pelo pensamento jurídico. É comum, a partir do séc. $\mathrm{V}$, a distinção entre a lei e a decisão judicial, assim como a indicação de que há algo, para além dos fatos do caso e do texto da lei, a intervir constitutivamente na decretação da sentença pelos juízes.

Na primeira parte do diálogo entre Sócrates e Eutiphron (Platão, Eutiphron, 3 a-d), Sócrates, à porta do Tribunal à espera da acusação e do julgamento, diz: "(...) não está realmente claro o que possa ocorrer, salvo para vocês, os adivinhos".

Também então surge a percepção do caráter injusto de uma decisão, mantendo-se embora a convicção na justiça da lei. A distinção entre a lei e a sentença aparece, por exemplo, no diálogo Críton, de Platão. Dizem as leis, no final do diálogo: "Pois bem: agora é certo que

Cohen são relevantes: importa não impor nossas categorias culturais (gnosiológicas, políticas) aos gregos, e especialmente evitar admitir qualquer sorte de lei reguladora do devir histórico. Esta crítica é nomeadamente dirigida por Cohen ao funcionalismo e ao positivismo. "Further, functionalism's most basic assumptions about the 'organic' nature of society have proved untenable in the light of new theoretical perspectives. Some critics have demonstrated the way in which functionalism provided an overly simplistic interpretation of social order because it assumed that social life must be rule-governed and that 'normal behavior' could be identified as compliance with normative precepts" (p. 12). No que se refere ao funcionalismo luhmanniano, não há dúvida de que a sua representação da passagem das sociedades sem direito para as sociedades juridicamente organizadas é um tanto esquemática. Servimo-nos dela, no entanto, pela lucidez com que acentua o direito como pensamento mediador entre fatos e normas, de um lado, e a decisão, do outro - mas, diferentemente de Luhmann, parece-nos haver entre os gregos elementos caracterizadores do pensamento jurídico como Dogmática Jurídica, embora não se possa falar de uma ciência do direito ainda. 
vais marchar para o Hades, se é que vais, vítima de uma injustiça - a qual te impingiram os homens, não nós, as leis (...)".

A tragédia também reflete sobre a ruptura da imediatidade entre lei e decisão judicial, problematizando o caráter contingente da verdade jurídica. A par do sentido tradicionalmente apontado pelos intérpretes da Oresteia $^{6}$, seu desfecho mostra o tribunal jurídico na sua específica função de decidir. É preciso decidir se Orestes é culpado pelo assassinato de sua mãe Clitemnestra - ele que a matou para cumprir o dever de vingar seu pai Agamenon.

Aquilo que o tribunal provê (diz) não surge sem a interveniência de uma decisão. Dada a problematicidade dos elementos dialogicamente trazidos pelas partes, é preciso instituir uma decisão - a qual precisou de uma deusa para ser forjada.

Sugere-se ser impossível ao homem resolver entre as diferentes possibilidades que se embatem no contraditório? A decisão, que vencerá a aporia, precisa do poder sobre-humano de um deus, para dar conta de superar o dissídio? ${ }^{7}$

Consciência da positividade do direito

O caráter problemático que o decidir assume entre os gregos liga-se a outro traço inovador da sua cultura, também característica do pensamento jurídico: a positividade do direito.

A positividade do direito, mais uma vez com Luhmann e Ferraz Jr., indica a consciência do jurista acerca do caráter contingente dos textos que funcionam como critério do decidir. Isto é, o jurista assume, como pontos de partida para o decidir, textos que são, por sua vez, fruto de uma outra decisão (do legislador). A lei é fruto de decisões humanas as quais

\footnotetext{
6 "Standard accounts of the history of legal institutions in Athens typically follow an evolutionary model: from an inherently unstable situation characterized by powerful aristocratic kingship groups, selfhelp, and weak central institutions emerges a civic legal order capable of regulating the cycles of feud and violence to which the previous instability had inevitably given rise. In literature, the moment in Athens' institutional history in which this new legal order established itself is captured in Aeschylus' Oresteia, which is depiction of the foundation of the first Athenian homicide court, the Areopagus. This dramatic foundational event represents the historical process by which the emerging polis wrested for itself the authority to enforce a final and binding resolution of disputes among its citizens." (COHEN, 1997, p. 3).

${ }^{7}$ A interpretação de Cohen (1997, p. 16-17) chama a atenção para o fato de que o julgamento que resulta da intervenção de Atena não é imparcial. "One can also read the Oresteia as a monument not to the end of feud, but to its incorporation into the world of the polis. The acquittal of Orestes turns more on the political relations of the parties than on considerations of justice, and the process of reaching judgment is by no means objective or unbiased. (Athena casts the deciding vote, but upon her entrance has already indicated her intimate connection to the defendant's family and stake in the war which has produced this familial catastrophe.)" Cohen continua (p. 18): "Rather than seeing the Oresteia as celebrating the foundation of civic justice one can also read it as commenting on the necessarily political grounding of all civic institutions, even those which claim to raise above the realm of politics." No contexto de nossa investigação aqui, o fechamento desta tragédia pode expressar o caráter dissídico, parcial, também da decisão judicial - a qual,
} vol.09, n. 03, Rio de Janeiro, 2016. pp. 
serão submetidas, nos julgamentos, a argumentação e reconstrução jurídica cujo telos é a decisão do juiz. O decidir figura assim nos dois extremos do pensamento jurídico ${ }^{8}$, que se mantém lúcido de que o texto da lei é uma opção entre outras alternativas possíveis, e de que estas outras possibilidades, antes descartadas pelo legislador, mantêm-se disponíveis para serem eventualmente assumidas por ele, numa decisão do legislador que venha a produzir nova lei no futuro.

Assinale-se ainda, para acentuar a consciência do grego com relação à gênese decisionista (e assim convencional, humana) da lei, a sua clareza quanto ao contexto de disputa entre as diferentes facções políticas, que marca o processo de decisão legislativa.

A invenção da lei como instituição social - que se dá também entre os gregos - está essencialmente ligada à consciência do dissídio que marca a sociedade grega. Os primeiros legisladores são convocados a partir da consciência do polemos, e para tentar superá-lo. Com o advento da democracia, torna-se mais aguda a consciência de que a lei resulta da disputa entre as parcialidades. A polêmica marcará todas as fases de experiência do direito, seja na produção da lei (guardando assim a positividade do direito um sentido de controvérsia, de abertura e disputa entre possibilidades) seja no decidir sobre os casos (estruturando-se, também a Dogmática jurídica, de acordo com um princípio polêmico).

A lei perde a fixidez que caracteriza os textos sagrados. ${ }^{9}$

Trata-se de uma mudança importante. Entre os gregos, a positividade da lei é experimentada e discutida de forma intensa. A lei, nomos, é assumida como obra humana ${ }^{10}$, e não como um dado natural, physis, para referir à terminologia com que a positividade da lei tornou-se consciente e foi problematizada entre os gregos: a tensão entre nomos e physis, que abriga diferentes aproximações do problema do surgimento da lei como obra humana. Disto decorrem importantes consequências em termos de problematicidade da experiência da justiça.

assim como os logoi das partes, não se encontra numa instância a salvo da antilógica. Isto ajuda a entender como o dissídio que marca a busca da verdade jurídica, no séc. V ateniense, é invencível, como veremos.

${ }^{8}$ Demóstenes (42.18) diz aos juízes: "Vocês conhecem a lei, ó Juízes, pois vocês a promulgaram". Sobre a identidade do demos como legislador e como julgador, na democracia ateniense, e seus efeitos na argumentação judicial, vide Cohen (1997, p. 185).

${ }^{9} \mathrm{O}$ caráter humano do decidir que produz a lei expressa-se ainda no sistema de responsabilização criminal dos cidadãos pela má participação na criação das leis. Trata-se do graphêe paranómon, "procedimento ateniense introduzido no decurso do século $\mathrm{V}$ a.C., através do qual qualquer cidadão poderia processar outro por este haver feito uma 'moção' ilegal na assembleia, mesmo que a assembleia soberana a tivesse aprovado" (FINLEY, 1997, p. 71). O cidadão é responsável, com seu patrimônio e sua vida, pela instituição de leis e decisões públicas, o que acentua ainda, e de modo trágico eventualmente, o caráter humano da instituição das leis.

${ }^{10} \mathrm{O}$ cidadão da Atenas democrática dedicava-se pessoalmente à feitura das leis. Apesar de toda reverência à lei, reiteradamente afirmada divina, ela tem a assinatura dos homens. Vetustas e respeitáveis porque feitas por legisladores antigos como Drácon ou Sólon, ou fruto da atuação da assembleia democrática, as leis são vol.09, nº 03, Rio de Janeiro, 2016. pp. 
O tema é central para a compreensão da cultura grega, e em especial do século V a.C. ${ }^{11}$ A contraposição entre physis e nomos é o mais importante testemunho do surgimento da consciência da positividade do direito. Intelectuais do século $\mathrm{V}$ dedicaram-se ao tema insistentemente, para discutir a legitimidade, a finalidade e os limites do poder humano de criar leis, assim como o dever de obedecê-las. Questiona-se a legitimidade para legislar, para tomar decisões que vincularão a comunidade - problematizando o ser humano como fundamento das leis.

Contrapor a natureza à convenção é perguntar pelo fundamento de legitimidade e pelos limites do poder de autodeterminação humana pela legislação. Muito embora as referências que a história da filosofia faça às afirmações da superioridade da physis sobre o nomos no séc. $\mathrm{V}$ ateniense enfatizem a afirmação de um direito natural, o que o surgimento da contraposição entre physis e nomos revela não é a existência de uma crença em leis não humanas - o que ela revela, de inovador, é o surgimento, e o espanto, com a existência de leis assumidamente humanas, resultantes de decisões tomadas por seres humanos na história.

O que surge de inovador na história das ideias com a contraposição entre physis e nomos não é a crença num fundamento sobre-humano da lei. Nisto acreditaram provavelmente todas as civilizações antigas. O que há de novo ali é exatamente a descoberta do ser humano como fundamento das leis, e a problematização disto.

Tal problematização é feita, no plano teórico-especulativo e prático-retórico, pelos intelectuais do século $\mathrm{V}$, em seus livros, aulas, demonstrações públicas e discursos forenses. ${ }^{12}$

A questão é especialmente tematizada na tragédia, que insiste na problematicidade invencível da existência humana - aguda reflexão sobre a transformação da cultura grega, com as novas concepções de ser humano e de comunidade que surgem a competir com as concepções arcaicas.

No íntimo de cada protagonista, encontra-se a tensão que notamos entre o passado e o presente, o universo do mito e o da cidade. A mesma personagem trágica aparece ora projetada

\footnotetext{
concebidas como fruto de uma decisão, opção entre outras possíveis, e reversível.

${ }^{11}$ Sonia Viegas fala da problematização do caráter natural da lei: "Na aurora do pensamento grego, assistimos à identificação entre Physis e Nomos, identificação que começa a ser questionada quando a postulação cosmológica da verdade deixa de servir de modelo para a Polis. A crise e o declínio da Polis se acompanha de uma ruptura entre esta e a Physis e, dessa forma, uma verdade pressuposta no interior da Physis, um logos imanente à realidade material, se revela insuficiente para justificar e fundamentar as questões humanas que eram vividas a nível político. Da crise da Polis emergem indagações decisivas sobre a verdade, sobre seu caráter absoluto, sobre sua relação com a Physis, sobre sua transcendência ou imanência com relação à existência temporal. Estas indagações convergem para o problema do homem: problema da significação e finalidade da sua existência, da sua liberdade e felicidade." (ANDRADE, 1982, P. 28).

${ }^{12}$ Para uma ampla investigação sobre a questão, fartamente documentada, vide Heinimann (1945) e Guthrie (1995).
} 
num longínquo passado mítico, herói de uma outra época, carregado por um poder religioso terrível, encarnando todo o descomedimento dos antigos reis da lenda - ora falando, pensando, vivendo na própria época da cidade, como um "burguês" de Atenas no meio de seus concidadãos. (VERNANT, NAQUET, 1989, p. 10).

A tragédia testemunha o advento da problematicidade do critério sobre o verdadeiro, o belo, o bom e o justo, na passagem do mundo do mito (em que tudo está estabelecido para o homem) para o mundo aberto à autoconstrução humana - tematizando exatamente os limites do poder do ser humano de colocar-se como fundamento da sua própria vida.

A afirmação de Protágoras - "o homem é a medida de todas as coisas" - sintetiza o sentido da cultura nascente e atinge o cerne de todo o sentimento de crise que ela traz. A tragédia expressa o desconforto e a dúvida acerca do homem como fundamento.

A tradição do ethos grego trazia consigo uma interrogação aparentemente sem resposta a respeito do domínio do homem sobre seu próprio agir - to ekousion - no qual consistia segundo a opinião comum o ser livre e, por conseguinte, responsável pelos próprios atos. Essa interrogação se torna mais aguda com o advento da individualidade, visível já nos primeiros líricos: como pode a livre individualidade conviver com a fatalidade do Destino (Moira)? A luta da liberdade com o Destino é o cenário grandioso onde se desenrola a prodigiosa criação literária da tragédia ática, último passo no caminho que conduzirá à criação socrática da Ética. Com efeito, como fazer conviver a universalidade cega do Destino com a universalidade luminosa da Razão, a primeira oprimindo ab extra o indivíduo impotente, a segunda fazendo emergir ab intra o espaço de sua liberdade? (VAZ, 1999, p. 62).

Trata-se, outra vez, da tensão entre physis e nomos como reflexão sobre os limites da instituição humana das leis.

Entre os testemunhos que ela oferece sobre o confronto entre o critério tradicional e imemorial e o critério simplesmente humano, histórico, do justo, Antígona, de Sófocles, contrapõe a lei humana (do rei Creonte) à lei sobre-humana invocada pela heroína.

Creonte - E tu, declara sem rodeios, sinteticamente. Sabias que eu tinha proibido essa cerimônia? Antígona - Sabia. Como poderia ignorá-lo? Falaste abertamente. Creonte - Mesmo assim ousaste transgredir minhas leis? Antígona - Não foi, com certeza, Zeus que as proclamou, nem a Justiça com trono entre os deuses dos mortos as estabeleceu para os homens. Nem eu supunha que tuas ordens tivessem o poder de superar as leis não escritas, perenes, dos deuses, visto que és mortal. Pois elas não são de ontem nem de hoje, mas são sempre vivas, nem se sabe quando surgiram. Por isso, não pretendo, por temor às decisões de algum homem, expor-me à sentença divina. Sei que vou morrer. Como poderia ignorá-lo? (1999, p. 35-36). 
Não é necessário insistir sobre a importância deste texto para a história da filosofia do direito. Especialmente os teóricos do direito natural começam sempre por ele a sua enumeração de testemunhos de leis superiores ao homem.

Outras concepções, sem orientação jusnaturalista, deveriam prestar-lhe também atenção. A tragédia grega não inova por afirmar a existência de leis supra-humanas e ahistóricas - mais uma vez, isso não seria nenhuma novidade entre os povos antigos - mas sim por testemunhar o surgimento de leis assumidamente humanas, as quais põem problemas que são, estes sim, inéditos. A existência de leis humanas é o que provoca a tragédia e lhe dá o sentido cultural, vindo a questionar este poder do homem - na Antígona, o poder de legislar de Creonte.

A trama não corre bem para Creonte, que é levado a reconhecer a superioridade da lei não humana. Mas a peça dá novo testemunho da positividade que marca a lei humana: Creonte, para evitar a morte do filho, noivo de Antígona, revoga a sentença de morte contra a irmã de Polinices:

Correi para aquela colina, que daqui se avista. Eu próprio, visto que mudei de resolução, eu próprio, que ordenei a prisão de Antígone, irei libertá-la! Agora, sim, eu creio que é bem melhor passar a vida obedecendo as leis que regem o mundo!

O limite do poder humano de legislar novamente aparece, pois mais uma vez o rei não alcançará seus objetivos: era tarde demais, e nada impede a morte de seu filho, como consequência da sua primeira decisão.

Sófocles põe em questão os limites da decisão humana, do poder do ser humano em colocar-se como fundamento de sua própria vida (da vida de cada um e da comunidade), ao decidir - permitindo refletir sobre os limites da positividade do direito.

Como reflexão sobre a positividade (o caráter humano) do fundamento das regras da convivência, a tragédia ajuda a construir o quadro de inteligibilidade do surgimento do pensamento jurídico como pensamento problemático que se apropria de fatos e leis no processo de construção da decisão.

Duas das mais importantes expressões da cultura do séc. V - a sofística e a tragédia trazem, portanto, com a tensão entre physis e nomos, uma problematização sobre a sociedade de todo importante para o desenvolvimento do pensamento jurídico, marcado pela positividade e pela decidibilidade.

POLEMOS COMO TRAÇO SINGULARIZADOR DA CULTURA GREGA 


\section{Criticismo e cultura filosófica}

Pensar a Atenas do século V é um desafio. Há uma espécie de pertencimento da nossa cultura à cultura grega, no sentido de uma genealogia: somos seus herdeiros, e por isso acreditamos sempre encontrar-nos ali. "Entre os gregos, sentimo-nos de imediato em casa", diz Hegel (1998, p. 189). Eles inventaram a política, a democracia, a filosofia, a lógica, a psicologia. Afirmaram valores sobre os quais insistimos ainda: a igualdade, a liberdade de expressão, a cidadania. Fizeram perguntas que ainda fazemos: Deus existe? Para que a vida humana? O que legitima a existência de leis?

Mas devemos esforçar-nos por compreender a cultura antiga em sua diferença, sem impor-lhe acriticamente as nossas categorias mentais.

O primeiro passo para compreender a cultura grega clássica em sua especificidade histórica será pensá-la como experiência de transformação, como invenção de novas formas de viver e de pensar. Os gregos, com a invenção da polis e da filosofia, vivem uma revolução que tem impacto sobre todas as dimensões da vida. A chamada passagem do mito para o logos implica em ampla reforma da visão de mundo, e instala uma forma de vida em que a revisão do saber, impulsionada pela crítica e pela dúvida, é permanente.

Os séculos em que esta passagem acontece não são tempos como os nossos. Hoje tudo talvez pareça mais ou menos assentado, leis da natureza e códigos legais. Já na Grécia clássica a sensação geral será de busca, de dúvida, de primazia do perguntar. É um tempo de questionamento, num ambiente polêmico em que novas formas de pensar declaram guerra contra as antigas. "Homero merecia ser expulso dos certames e açoitado, e Arquíloco igualmente", terá escrito Heráclito (FRAGMENTE DER VORSOKRATIKER. frag. 42). A passagem do mito ao logos não se dá sem grandes tensões.

A passagem do mito ao logos tem grande amplitude cultural. Ela diz respeito a todas as dimensões da vida. Surge uma forma cultural fundada em novos modos de pensar e comunicarse: uma nova atitude espiritual, no sentido empregado por Husserl (2006). Falando sobre a gênese da civilização ocidental, ele propõe um conceito amplo de Filosofia como atitude espiritual, entendida como uma forma de viver fundada sobre determinada visão do mundo.

'Atitude espiritual' é a visão de mundo que anima fundamentalmente cada experiência cultural, condicionando a compreensão que os homens têm de si mesmos e de tudo à sua volta (deuses, astros, leis). Husserl descreve a passagem do mito para o logos como a passagem de uma atitude espiritual fundada na certeza aproblemática sobre os fundamentos da vida (veiculadas pelo mito) para uma atitude espiritual fundada na dúvida e na problematização 
infinita. Muda a relação com o saber, que se descobre agora sempre criticável. A civilização filosófica é uma civilização fundada na dúvida, porque admite que tudo o que se sabe é precário e revisível.

Com a revolução cultural ocorrida entre os séculos VIII e IV, impulsionada por transformações econômico-culturais importantes como o advento da polis, a instituição da moeda e o letramento, a atitude espiritual anterior à Filosofia - representada pela forma de vida mito-poeticamente fundada e reproduzida - dá nascimento a uma outra, marcada por um caráter investigativo e crítico, com a qual passa a conviver. $\mathrm{O}$ mundo passa a ser objeto de questionamento permanente. As estórias (mitos) passadas de geração a geração para explicar o mundo e a vida humana já não bastam, e passa-se a investigar tudo, com apoio apenas no mundo tal como se mostra. "Pois é preciso que de muitas coisas sejam inquiridores os homens amantes da sabedoria", escreveu Heráclito (FRAGMENTE DER VORSOKRATIKER, frag. 35), expressando a característica fundamental da nova cultura: a procura.

\section{Polemos e cultura filosófica}

Todo este questionamento não acontece obviamente sem reação.

A cultura filosófica propõe uma transformação radical do modo de viver, polemizando com a atitude mito-poética. A forma tradicional de vida é investigada e refutada em seus fundamentos mais caros (a natureza dos astros; a existência de deuses; a superioridade dos nobres ou mesmo dos homens sobre as mulheres, ou dos gregos sobre os bárbaros; a coragem como a virtude capital; a justiça como o ajudar os amigos e prejudicar os inimigos; o caráter natural da existência política etc.).

Instala-se, entre as duas concepções de vida em contraste, uma grande polêmica em que desde o riso até a morte foram usados como armas.

Mas a polêmica não resulta apenas da tensão entre mito e logos como visões de mundo disputantes, mas dá-se também entre as próprias formas de pensar que nascem no interior da cultura filosófica. Isto é, as diferentes expressões da nova cultura também combatem entre si. O quadro é de uma grande polêmica entre intelectuais (sábios, sofistas e filósofos, uns contra os outros), a envolver também oradores, poetas, escritores de tragédias, de comédias etc. todos representantes da nova cultura inaugurada com a Filosofia) - em relação tensa, ao mesmo tempo, com o saber tradicional.

Tudo se mantém em questionamento e crítica. Propõem-se novas formas de pensar, ligadas a novas formas de falar e de escrever, sobre absolutamente todas as questões. Está em 
disputa o que é pensar e o que é viver. Nada - nem a existência dos deuses, nem as mais arraigadas concepções de justiça e de bondade - escapam ao espírito inquiridor e polêmico.

No século VI, os pré-socráticos disputam sobre as substâncias e os princípios a partir de que tudo advém. Será a água como quer Tales, o ar como quer Anaxímenes, ou o fogo como quer Heráclito? Ou serão homeomerias, como quer Anaxágoras, ou átomos, como depois, já no século V, diria Demócrito? Com maior foco no ser humano, os intelectuais do séc. V mantêmse em disputa sobre o que é pensar, a justiça, linguagem, a origem e a natureza da sociedade, agir etc.

\section{Filosofia e disputa política}

A nascente cultura do questionamento está ligada a duas novidades históricas: a polis, entendida como vida em comum entre homens iguais e livres, e a lei, entendida como regra da convivência política , isto é, como regra da coexistência entre homens livres e iguais.

A política é dimensão essencial da cultura filosófica. Ela valoriza a palavra, o discurso, e estimula o livre pensar que está na base da atitude crítica e investigativa.

"A justiça é a ordem (taxis) da polis" (Política, I, 1252a37-38); "parece a todos que o justo é uma certa igualdade" (Política, III,1282b18). A igualdade é o fundamento instituidor da polis.

Na Ética a Nicômaco, a que remete a passagem acima, mais uma vez se afirma a implicação entre igualdade, política e lei:

Parece também evidente, por outro lado, que justo será quem observa a lei e respeita a igualdade. Disposição justa é, então, por um lado, a observância da lei e o respeito pela igualdade; disposição injusta, por outro, é a transgressão da lei e o desrespeito pela igualdade. (Ética a Nicômaco, 1129a-b) (...) Ora se a injustiça é iniquidade, então a justiça é igualdade. (Ética a Nicômaco, 1131 a 10-15).

A associação política, em que os homens põem-se lado a lado como iguais, é uma formação social tensa, percebida como em permanente risco. Este risco é causado pela tensão invencível entre as diferentes concepções que disputam a polis, propondo-lhe diferentes fundamentos e regimes. Especialmente a democracia, regime que atinge maior estabilidade na Atenas clássica, é marcada ela própria pela abertura para a disputa, assumida como uma construção de que todos os cidadãos participam.

A igualdade nunca deixou de ser uma experiência problemática entre os gregos. A disputa pela polis é uma disputa sobre o sentido e a amplitude da igualdade, que uns, ao lado 
do povo, pretendem alargar, e outros, oligárquicos ou aristocráticos, pretendem restringir. $\mathrm{Na}$ medida em que a lei determina a amplitude da igualdade, sua elaboração e interpretação mantêm-se em viva disputa. A feitura da lei dá-se num horizonte polêmico, o que institui o desafio do legislador.

O dissídio político-social que ameaça a cidade oferece o contexto para compreendermos o sentido da justiça como problema central da cultura grega. A justiça, e assim a lei, representam o esforço por superar o dissídio que ameaça a sobrevivência da cidade. Ambas só fazem sentido, por isso, sobre o pano de fundo do dissídio permanente que marca a cidade.

A isenção da lei face ao dissídio político é vista como um ideal. Mas as partes em disputa não deixam de instrumentalizá-la, sempre que podem. Isto contribui para acentuar a crise da forma política, e a sensação de que não há um porto seguro - a salvo do dissídio - para fundamentar a convivência política.

$\mathrm{O}$ advento da democracia e a ampliação do direito de igualdade e participação a camadas mais amplas do povo estão na raiz da discussão sobre o caráter natural ou convencional da sociedade e da virtude. A oposição entre physis e nomos deve ser também pensada neste quadro de disputa pela polis. Ela guarda lugar para diferentes posicionamentos sobre o regime político, e sobre a reflexão acerca dos fundamentos da polis e seus fins.

Neste horizonte, compreende-se a atividade dos sofistas, sobre a qual deixamos uma última palavra neste tópico.

Saber falar em público, ser capaz de participação qualificada na Ágora, é dom natural do ponto de vista de um aristocrata, que tende a confundir ser bem nascido (physis) com ser bem educado. Mas as coisas mudam com a democracia, quando pessoas vulgares (não nobres) passam a exercer esta atividade e a valorizar este poder. Isto demanda uma nova atividade intelectual: surgem professores de retórica, que têm então grande prestígio em toda Hélade democrática.

A virtude passa a ser ensinada e aprendida, deixando de ser vista como um dom natural. Acentua-se a consciência do fundamento histórico (não natural) da vida humana, percebendo-se que tanto o destino de uma pessoa como o da comunidade dependem de ações e decisões humanas. Estão, enfim, não sob a égide da natureza, mas da história, expondo-se, assim, à disputa, ao polemos que marca as coisas humanas, tal como o grego as sente.

GREEK LAW? POSITIVITY, PROBLEMATICITY AND DECISION IN vol.09, n. 03, Rio de Janeiro, 2016. pp. 


\title{
ANCIENT GREEK LEGAL EXPERIENCE
}

\begin{abstract}
This article assumes Luhmann and Ferraz Jr.'s perspective of legal knowledge. These authors state that lawyers' reasoning focuses on decision and prepares it throughout an argumentative opening of facts and criteria of social life to problematization. The article focuses on the presence of these traits of legal reasoning in Ancient Greek.
\end{abstract}

Keywords: Ancient Greece. Law. Legal reasoning. Philosophical Culture.

\section{REFERÊNCIAS}

\section{Fontes Primárias}

ANCILLA TO THE PRE-SOCRATIC PHILOSOPHERS: a complete translation of the fragments in Diels, "Fragmente der Vorsokratiker". Trad. Kathleen Freeman. Oxford: Harvard University Press, 1983.

ANTIFONTE. Testemunhos, fragmentos, discursos. Trad. Luis Felipe B. Ribeiro. São Paulo: Loyola, 1998.

ARISTÓTELES. A política. Trad. Nestor Silveira Chaves, 4. ed., São Paulo: Atena Editora, 1955.

ARISTÓTELES. Ética a Nicómaco. Trad. António C. Caeiro. São Paulo: Atlas, 2009.

DEMÓSTENES. Volume IV. Orations 27-40: Private Cases. Trad. A. T. Murray. Cambridge, MA, Harvard University Press; London, William Heinemann. 1939. Disponível em: <www.perseus.tufts.edu>. Acesso em: 03/08/2009.

FRAGMENTE DER VORSOKRATIKER. Hermann Diels, Walther Kranz. Hidessheim: Weidmann, 1989.

PLATÃO. Críton. Trad. Francisco Garcia Yagüe. In: PLATON. OBRAS COMPLETAS. Madri: Aguilar, 1974, p. 225-232.

PLATÃO. Euthyphro. Trad. Harold North Fowler. Cambridge, MA: Harvard University Press, 1966.

SOFISTAS. Testemunhos e fragmentos. Trad. Ana A. A. Souza, Maria J. V. Pinto. Lisboa: Imprensa Nacional - Casa da Moeda, 2005.

SÓFOCLES. Antígona. Trad. Donadlo Schuller. Porto Alegre: L\&PM, 1999.

THE GREAT SOPHISTS. Translation, introduction and notes by John Dillon and Tania Gergel. London: Penguin Books, 2003. 


\section{Fontes Secundárias}

ANDRADE, Sônia Maria Viegas. De Hegel a Kierkegaard. O problema existencial e a consciência infeliz. Boletim SEAF, n. 1, 1982.

COELHO, Nuno M. M. S. Direito, Filosofia e a humanidade como tarefa. Curitiba: Juruá, 2011.

COELHO, Nuno M. M. S. Pessoa, Igualdade (Isegoria) e Controvérsia. Notas sobre o sentido da ideia de Direito, (co)fundadora da experiência civilizacional ocidental. Revista da Faculdade de Direito do Sul de Minas, v. 25, p. 183-192, 2007.

COHEN, David. Law, violence and community in classical Athens. Cambridge: Cambridge University Press, 1997.

COHEN, David; GAGARIN, Michael. (Eds.). The Cambridge Companion to ancient Greek law. Cambridge: Cambridge University Press, 2005.

FERRAZ JR., Tercio Sampaio. A função social da dogmática jurídica. São Paulo: Max Limonad, 1998.

FERRAZ JR., Tercio Sampaio. Introdução ao estudo do direito: técnica, decisão, dominação. São Paulo: Atlas, 1988.

FINLEY, Moses. Política no mundo antigo. Trad. Gabinete Editorial de Edições 70. Lisboa: Edições 70, 1997.

GUTHRIE, W. K. C. Os sofistas. Trad. João Resende Costa. São Paulo: Paulus, 1995.

HARRISON. A. R. W. The law of Athens. Volume I. London: Gerald Duckworth; Indianopolis/Cambridge: Hackett Publishing, 1984.

HEGEL, Georg Wilhelm Friedrich. Filosofia da história. Trad. Maria Rodrigues, Hans Harden. 2. ed. Brasília: Universidade de Brasília, 2008.

HEINIMANN, F. Nomos und Physis. Herkunft und Bedeutung einer Antithese. Basilea, 1945.

HUSSERL. Edmund. A crise da humanidade europeia e a filosofia. Trad. Pedro M. S. Alves. Fundamentos e Fronteiras do Direito. Barbacena, v. 1, n. 2, 2006.

LUHMANN, Niklas. Rechtssoziologie. 2 volumes. Reinbek: Rowohlt, 1972.

LUHMANN, Niklas. Sociologia do Direito. 2 volumes. Trad. Gustavo Bayer. Rio de Janeiro: Tempo Brasileiro, 1983.

VERNANT, Jean-Pierre. As origens do pensamento grego. Trad. I. Borges B. Fonseca. 2. ed. Rio de Janeiro, São Paulo: DIFEL, 1977.

VERNANT, Jean-Pierre. As origens do pensamento grego. Trad. Ísis Borges B. da Fonseca. São Paulo: Bertrand Brasil, 1989. 
VERNANT, Jean-Pierre. Entre mito e política. Trad. Cristina Murachco. São Paulo: EDUSP, 2002.

VERNANT, Jean-Pierre; VIDAL-NAQUET, Pierre. Mito e tragédia na Grécia antiga. Trad. Anna Lia A. de Almeida Prado et al. São Paulo: Perspectiva, 2005.

\section{Obra de Referência}

LIDDELL, Henry George; SCOTT, Robert. A Greek-English Lexicon. Oxford. Clarendon Press. 1940. Disponível em: <www.perseus.tufts.edu〉. Acesso em: 14/10/2010.

Trabalho enviado em 10 de julho de 2016.

Aceito em 17 de julho de 2016. 